Research Article

\title{
Numerical Investigation of Influences of Drilling Arrangements on the Mechanical Behavior and Energy Evolution of Coal Models
}

\author{
Tong-bin Zhao $\mathbb{i D}^{1,2,3}$ Wei-yao Guo $\mathbb{i D}^{1,2,3}$ Feng-hai Yu $\mathbb{D}^{1},{ }^{1,2,3}$ Yun-liang Tan $\mathbb{i},,^{1,2,3}$ \\ Bin Huang, ${ }^{1,2}$ and Shan-chao $\mathrm{Hu} \mathbb{(}^{1,2}$ \\ ${ }^{1}$ State Key Laboratory of Mining Disaster Prevention and Control Co-founded by Shandong Province and the Ministry of Science \\ and Technology, Shandong University of Science and Technology, Qingdao 266590, China \\ ${ }^{2}$ College of Mining and Safety Engineering, Shandong University of Science and Technology, Qingdao 266590, China \\ ${ }^{3}$ National Demonstration Center for Experimental Mining Engineering Education, \\ Shandong University of Science and Technology, Qingdao 266590, China
}

Correspondence should be addressed to Wei-yao Guo; 363216782@qq.com and Feng-hai Yu; yufenghai2006@163.com

Received 8 October 2017; Accepted 29 January 2018; Published 23 April 2018

Academic Editor: Hang Lin

Copyright $\odot 2018$ Tong-bin Zhao et al. This is an open access article distributed under the Creative Commons Attribution License, which permits unrestricted use, distribution, and reproduction in any medium, provided the original work is properly cited.

\begin{abstract}
Destress drilling method is one of the commonly used methods for mitigating rock bursts, especially in coal mining. To better understand the influences of drilling arrangements on the destress effect is beneficial for rock burst mitigation. This study first introduced the rock burst mitigation mechanism of the destress drilling method and then numerically investigated the influences of drilling arrangements on the mechanical properties of coal models through uniaxial compression tests. Based on the test results, the energy evolution (i.e., the energy dissipation and bursting energy indexes) influenced by different drilling arrangements was analyzed. When the drilling diameter, the number of drilling holes in one row, or the number of drilling rows increases, the bearing capacity of specimens nonlinearly decreases, but the energy dissipation index increases. In addition, the drilling diameter or the number of drilling holes in one row affects the failure mode weakly, which is different from that of the number of drilling rows. Consequently, the bursting energy index decreases as increasing the drilling diameter or the number of drilling holes in one row, but as increasing the number of drilling rows, the variation law of bursting energy index is not obvious. At last, the influencing mechanism of drilling arrangement on the rock burst prevention mechanism of the destress drilling method was discussed and revealed.
\end{abstract}

\section{Introduction}

With the worldwide economic and social development, the shallow mineral resources are gradually depleted, and the depth of mining or tunnelling is deeper and deeper [1-4]. Rock burst has become one of the serious dynamic disasters in deep exploitation [5-10]. According to the statistics, there were more than 140 coal mines threatened by rock bursts in China [11]. Fortunately, scholars have achieved a series of significant achievements related to rock bursts in mechanisms, monitoring, and warning techniques, and preventing and controlling techniques $[12,13]$. Despite decades of researches, some aspects still need to be improved, and its control remains a critical research point.

The commonly used mitigation methods include destress blasting performed in coal seams and compete rock layers, water infusion of coal seam, and destress drilling [14, 15]. Among these methods, the destress drilling method also has become popular due to its convenient construction in China $[11,16]$, and scholars have done lots of work related to destress drilling. Regarding the experimental and numerical researches, Liu et al. [11] studied the relief mechanism of destress drilling for rock burst prevention through laboratory tests and proposed a method for determining the drilling parameters; 


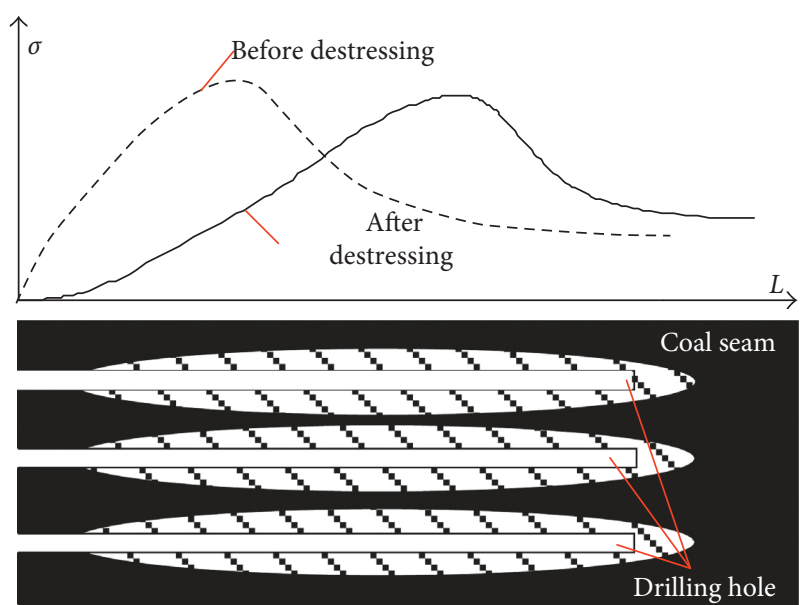

Figure 1: Sketch of destress drilling in coal seam.

Jia et al. [17] researched the destress mechanism of largediameter drilling by laboratory and numerical studies; and Liu et al. [18], Li et al. [19], and Yi et al. [20] numerically researched the diameter, space, and length of the drilling hole on the destress effect. Regarding the theoretical and field researches, Zhu et al. [16] proposed an energy dissipation index method for determining drilling parameters, and Song et al. [21] and $\mathrm{Ma}$ et al. [22] researched the collaborative control of destress drilling and roadway support.

Above researches mainly focus on the destress mechanism and on the destress effect by comparing parameters, but the drilling arrangement also has an essential influence on the destress effect of the drilling method. However, there are few literatures trying to reveal the influences of drilling arrangements on the destress effect of the drilling method systematically. Therefore, this paper first introduced the rock burst mitigation mechanism of destress drilling performed in coal seams. Then, we numerically investigated the influences of various drilling arrangements, including the drilling diameter, the number of drilling holes in one row, and the number of drilling rows, on the mechanical properties of coal models. Based on the test results, the energy evolution influenced by various drilling arrangements and their influencing mechanisms on the destress effect of the drilling method were analyzed and discussed. This study can provide a basic reference for understanding the influences of drilling arrangements on the destress effect of drilling method.

\section{Rock Burst Mitigation Mechanism of Destress Drilling Method}

As one of the widely used methods for mitigating rock bursts in China, the destress drilling method is that drilling boreholes with large-diameters in the stress or possible stress concentration areas in coal seams. When drilling boreholes in the stress concentration area, X-shape areas of plastic deformation will form around these holes [23]. If the density of drilling boreholes is high enough, these plastic areas will be connected each other and thus a larger destressed area will form, leading to the transfer of high stress concentration area into the deep coal wall, as shown in Figure 1. Generally speaking, the destress drilling method mainly functions through stopping the formation or mitigating the stress concentration of high stress concentration areas [11]. When it is used for premitigating stress concentration, its prevention mechanism of rock bursts is changing the mechanical parameters of coal/rock and decreasing its ability of strain energy accumulation; when it is used for preventing rock bursts, its prevention mechanism is dissipating the accumulated strain energy and increasing the resistant force.

\section{Numerical Investigation of Influences of Drilling Arrangements on the Mechanical Behavior of Coal Models}

\subsection{Discrete Element Model}

3.1.1. Microbond Model. In PFC2D, there are two kinds of failure modes between particles, that is, the shear failure and the tension failure. It has two different bond models-contact bond model (CBM) and parallel bond model (PBM) - generally used for simulating granular materials and compact materials, respectively. There are two advantages for the PBM: first, parallel bonds can transmit both forces and moments between particles; second, bond breakage can lead to immediate decrease in macrostiffness. Thus, the PBM can be more realistic for simulating rock materials because the bonds can break in either tension or shearing as the stiffness reduces [24]. In this paper, we chose the PBM to carry out the numerical simulation.

3.1.2. Numerical Specimens with Various Drilling Arrangements and Simulation Procedure. The height and width of numerical specimen were $100 \mathrm{~mm}$ and $50 \mathrm{~mm}$, respectively [25]. The numerical specimen was discretized into 11,693 particles. The particle size followed a uniform distribution varying from 0.3 to $0.4 \mathrm{~mm}$. The density was about $1600 \mathrm{~kg} / \mathrm{m}^{3}$. After generating the specimen, we established coal models with various drilling arrangements by deleting ball particles. The drilling arrangement mainly includes three parameters, that is, drilling diameter, number of drilling holes in one row, and number of drilling rows. Since this paper mainly researches the influences of drilling arrangements on the destress effect in detail, three kinds of test schemes were designed; that is, scheme I considering the influence of drilling diameter, scheme II considering the influence of the number of drilling holes in one row, and scheme III considering the influence of the number of drilling rows, as shown in Figure 2. In scheme I, the numbers of drilling holes and drilling rows are all set to 1 while the drilling diameter varied from 3 to $10 \mathrm{~mm}$, as shown in Figure 2(a); in scheme II, the number of drilling rows and the drilling diameter are set to 1 and $3 \mathrm{~mm}$, respectively, while the number of drilling holes in one row varied from 1 to 4 , as shown in Figure 2(b); in scheme III, the number of drilling holes and the drilling diameter are set to 3 and $3 \mathrm{~mm}$, respectively, while the number of drilling rows varied from 1 to 4 , as shown in Figure 2(c). Detailed description of test schemes is listed in Table 1. 

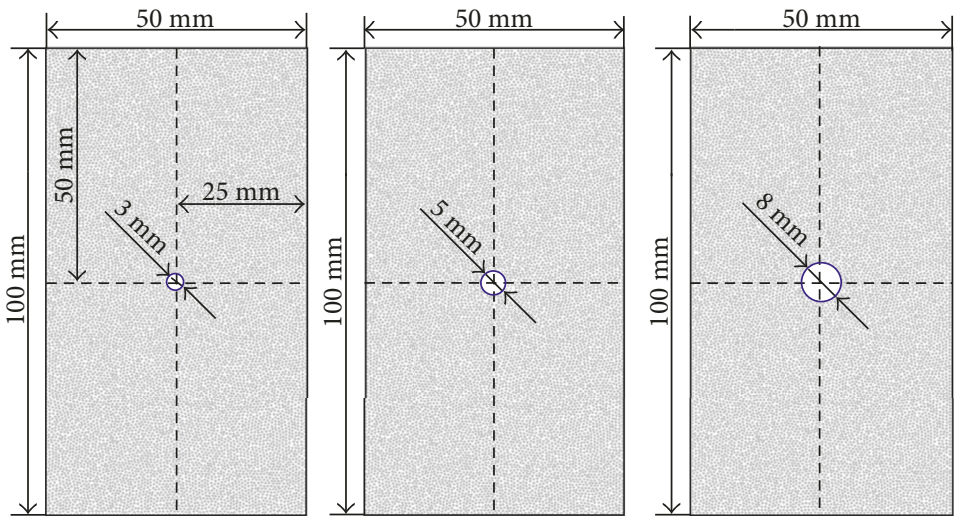

(a)
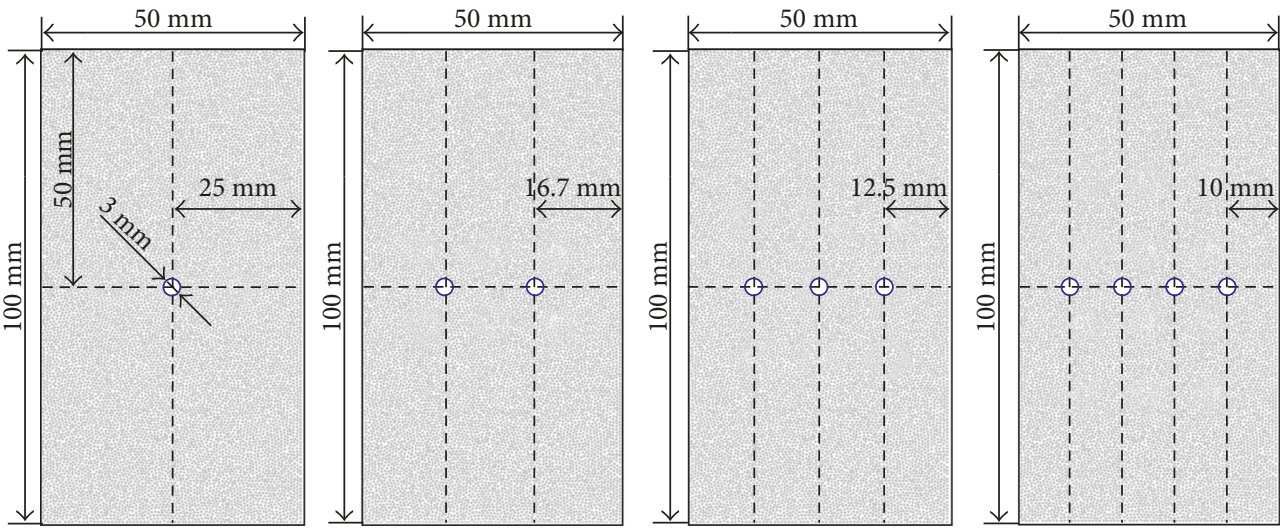

(b)
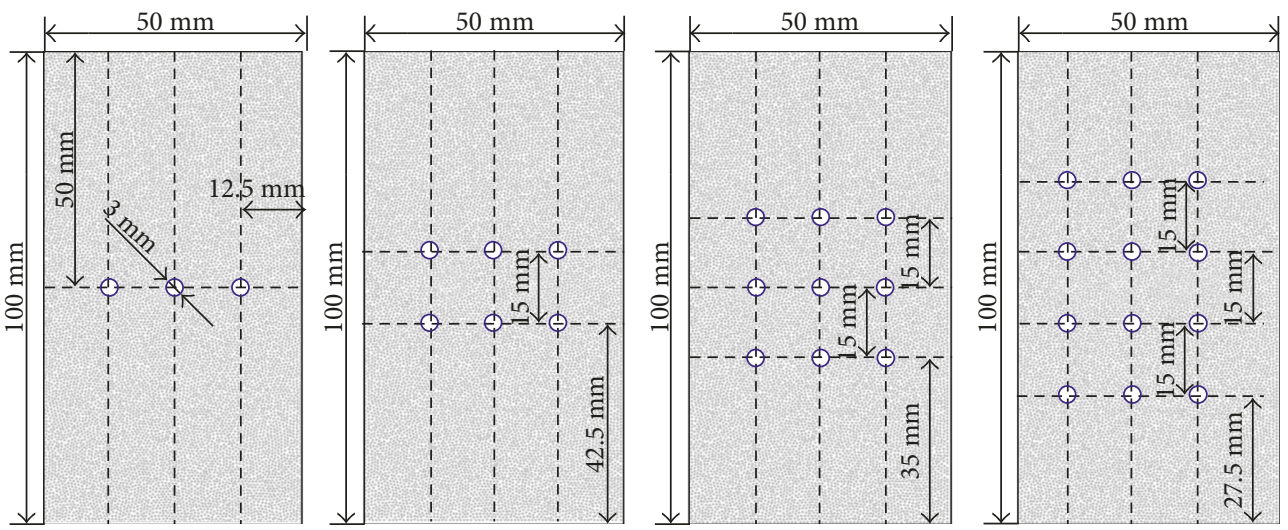

(c)

Figure 2: Schematic diagram of test schemes. (a) Specimens with different drilling diameters. (b) Specimens with different numbers of drilling holes. (c) Specimens with different numbers of drilling rows.

An external displacement was applied on the top of the specimen in the axial direction. The loading rate must be low for ensuring that the specimen remained in a quasistatic state throughout the simulation process. Zhang and Wong [26] researched the influence of loading rate on the mechanical behavior of specimens containing prefissures, which showed that the crack initiation stress, and uniaxial compressive strength remained steady when the loading rate increased from $0.005 \mathrm{~m} / \mathrm{s}$ to $0.08 \mathrm{~m} / \mathrm{s}$. Therefore, the loading rate of $0.05 \mathrm{~m} / \mathrm{s}$ was chosen in this numerical simulation, and the loading was applied until the failure occurred.

\subsection{Confirmation for Microparameters of Rock-Like Material}

3.2.1. Confirming Method for Microparameters. Determining the microparameters for numerical simulation is difficult by experiment, but it is essential to establish a correlation between the macrobehavior and microparameters for validating the particle properties used in numerical specimens. The macrobehavior includes the stress-strain curve, peak stress, elastic modulus, and failure mode [27-29]. The trial and error method was used in confirming the microparameters. The macrobehavior of coal material obtained by 
TABLE 1: Test schemes.

\begin{tabular}{lccc}
\hline Test scheme & $R_{\mathrm{D}}(\mathrm{mm})$ & $N_{\mathrm{H}}$ & $N_{\mathrm{R}}$ \\
\hline I & $3,5,8,10$ & 1 & 1 \\
II & 3 & $1,2,3,4$ & 1 \\
III & 3 & 3 & $1,2,3,4$ \\
\hline
\end{tabular}

Note. $R_{\mathrm{D}}, N_{\mathrm{H}}$, and $N_{\mathrm{R}}$ are the drilling diameter, the number of drilling holes in one row, and the number of drilling rows, respectively.

TAble 2: Microparameters used in the PFC2D model.

\begin{tabular}{lc}
\hline Microparameters & Values \\
\hline Elastic modulus of the particle, $E_{\mathrm{c}}(\mathrm{GPa})$ & 0.45 \\
Parallel-bond radius multiplier & 1.0 \\
Ratio of normal to shear stiffness of the particle, $k_{\mathrm{n}} / k_{\mathrm{s}}$ & 2.5 \\
Ratio of normal to shear stiffness of the parallel bond, & 2.5 \\
$\bar{k}_{n} / \bar{k}_{s}$ & 0.5 \\
Particle friction coefficient, $\mu$ & 8.75 \\
Parallel-bond normal strength, $\sigma_{\mathrm{n}}(\mathrm{MPa})$ & 10.5 \\
Parallel-bond shear strength, $\tau_{\mathrm{n}}(\mathrm{MPa})$ & \\
\hline
\end{tabular}

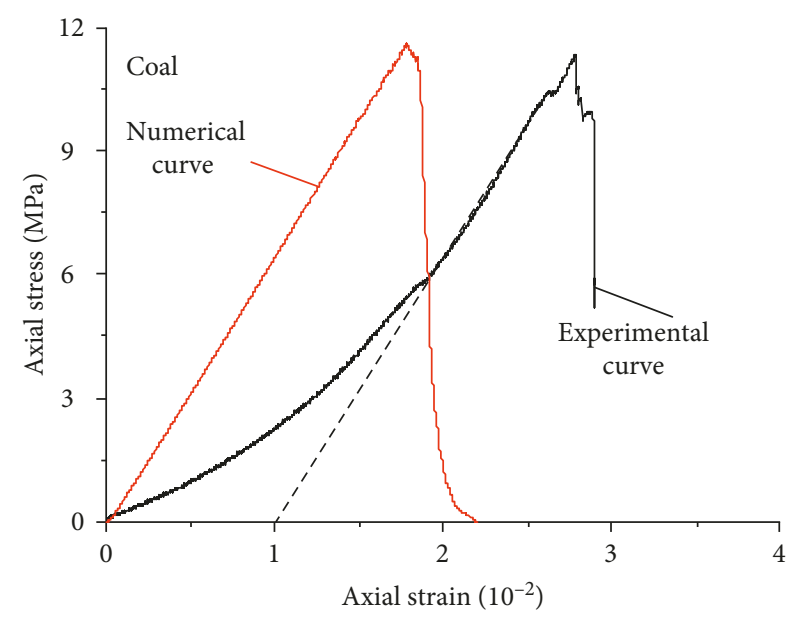

Figure 3: Comparison between experimental and numerical stressstrain curves of coal under uniaxial compression.

experiment was used to calibrate the microparameters. After each trial, the macroscopic results obtained by the numerical simulation were used to compare with the experimental results. This process was repeated until the numerical results were similar to the experimental results.

The microparameters used in the PFC2D model are listed in Table 2. The elastic modulus of the particle is $0.45 \mathrm{GPa}$. The ratio of normal to shear stiffness of the particle and the parallel bond is 2.5. The particle friction is 0.5 . The values of parallelbond normal strength $\left(\sigma_{\mathrm{n}}\right)$ and parallel-bond shear strength $\left(\tau_{\mathrm{n}}\right)$ are $10.5 \mathrm{MPa}$ and $8.75 \mathrm{MPa}$, respectively.

\subsubsection{Calibration of Microparameters by Experimental} Results. The comparison between experimental and numerical stress-strain curves under uniaxial compression is shown in Figure 3. It can be seen that both the numerical curve and the experimental curve include elastic deformation stage, crack initiation and growth stages, and unstable failure stage. However, the experiment specimen also has the stage
TABLE 3: Comparison between the experimental and numerical mechanical parameters.

\begin{tabular}{lcc}
\hline $\begin{array}{l}\text { Mechanical } \\
\text { parameters }\end{array}$ & $\begin{array}{c}\text { Experimental } \\
\text { results }\end{array}$ & $\begin{array}{c}\text { Numerical } \\
\text { results }\end{array}$ \\
\hline$\sigma_{\mathrm{c}}(\mathrm{MPa})$ & 11.32 & 11.57 \\
$E(\mathrm{GPa})$ & 0.74 & 0.70 \\
\hline
\end{tabular}

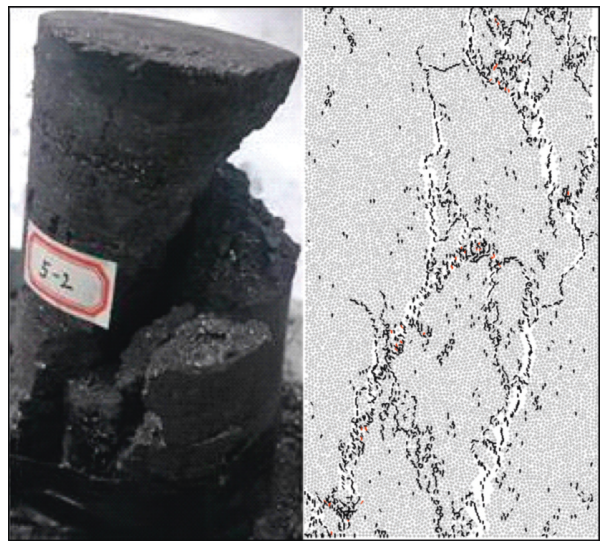

FIGURE 4: Comparison between experimental and numerical failure modes of coal under uniaxial compression test. The black and red dots represent the tensile microcrack and shear microcrack, respectively.

of compaction and nonlinear deformation at low stress levels, which are not observed in the numerical specimen. This is because the experimental specimen contains primary cracks, pores, and voids.

The comparison of mechanical parameters between the experimental results and the numerical results is listed in Table 3. In Table 3, $\sigma_{\mathrm{c}}$ is defined as the uniaxial compressive strength, and $E$ refers to the slope of the linear part of the stress-strain curve. In accordance with Table 3, it shows clearly that the simulated peak stress and elastic modulus are almost equal to those obtained by the experiment.

The comparison between the experimental and numerical failure modes is depicted in Figure 4. Figure 4 illustrates that the failure mode of rock-like specimen is axial splitting under numerical simulation, which is similar to that obtained by experiment. The comparisons shown in Figures 3 and 4 calibrate the rightness and reasonability of microparameters used in Table 2.

\subsection{Numerical Results}

3.3.1. Overall Stress-Strain Curves. Stress-strain curves of specimens with different drilling arrangements under uniaxial compression are shown in Figure 5. In accordance with Figure 5, we can conclude that the compression strength of specimens decreases gradually as increasing the drilling diameters, the number of drilling holes in one row, or the number of drilling rows, which will be analyzed in detail in the following sections.

Table 4 lists the mechanical properties of specimens with different drilling arrangements, that is, the uniaxial compressive 


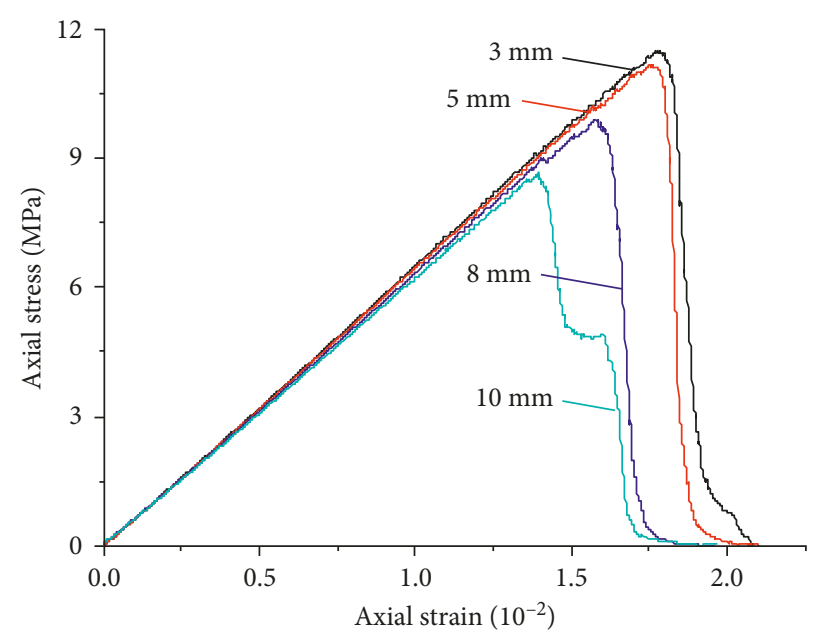

(a)

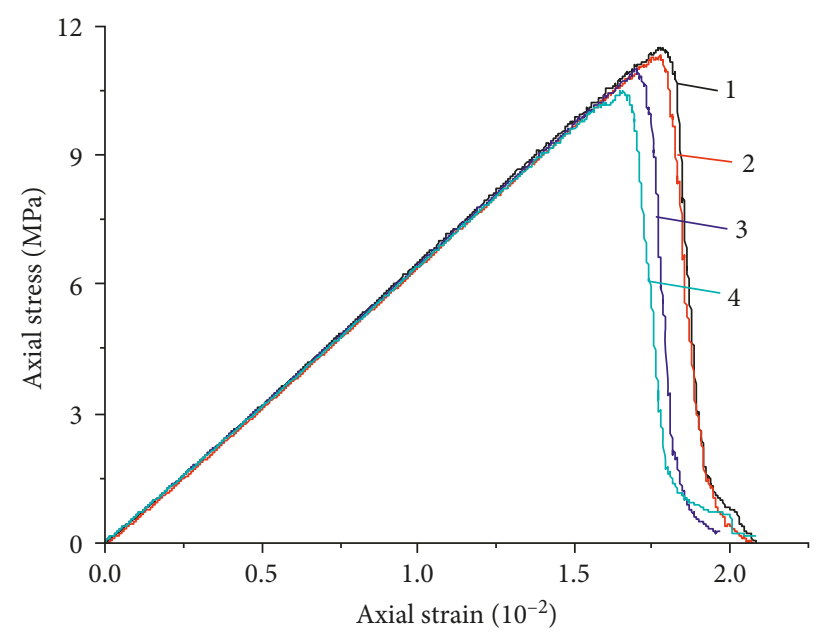

(b)

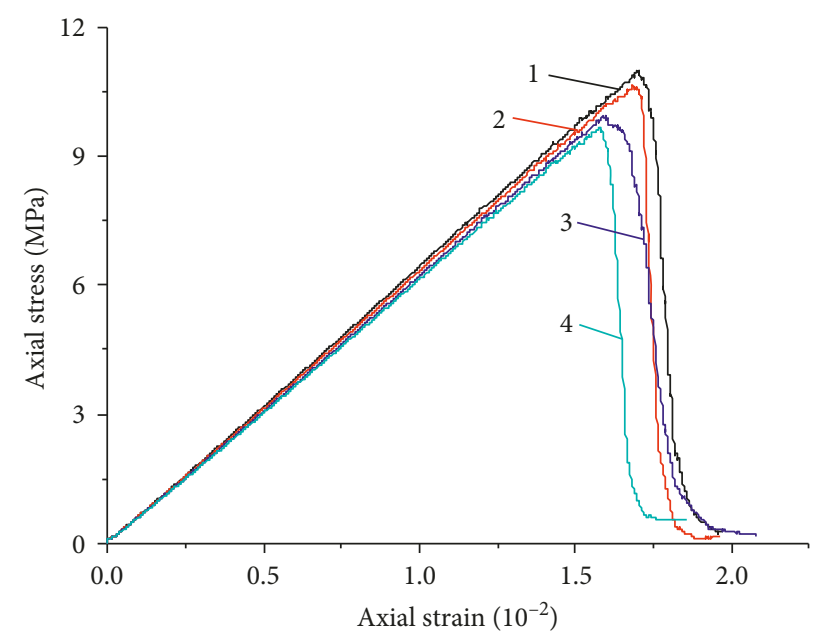

(c)

FIGURE 5: Stress-strain curves of specimens with different drilling arrangements under uniaxial compression. (a) Different drilling diameters. (b) Different numbers of drilling holes. (c) Different numbers of drilling rows.

TABLE 4: Mechanical properties of specimens with different drilling arrangements.

\begin{tabular}{|c|c|c|c|c|c|c|}
\hline Test scheme & $R_{\mathrm{D}}(\mathrm{mm})$ & $N_{\mathrm{H}}$ & $N_{\mathrm{R}}$ & $\sigma_{\mathrm{c}}(\mathrm{MPa})$ & $E(\mathrm{GPa})$ & $\varepsilon_{1 \max }\left(10^{-2}\right)$ \\
\hline \multirow{4}{*}{ I } & 3 & \multirow{4}{*}{1} & \multirow{4}{*}{1} & 11.48 & 0.66 & 1.7863 \\
\hline & 5 & & & 11.17 & 0.65 & 1.7551 \\
\hline & 8 & & & 9.89 & 0.64 & 1.5766 \\
\hline & 10 & & & 8.64 & 0.63 & 1.3926 \\
\hline \multirow{4}{*}{ II } & \multirow{4}{*}{3} & 1 & \multirow{4}{*}{1} & 11.48 & 0.66 & 1.7863 \\
\hline & & 2 & & 11.41 & 0.65 & 1.7804 \\
\hline & & 3 & & 11.01 & 0.65 & 1.6993 \\
\hline & & 4 & & 10.46 & 0.64 & 1.651 \\
\hline \multirow{4}{*}{ III } & \multirow{4}{*}{3} & \multirow{4}{*}{3} & 1 & 11.01 & 0.65 & 1.6993 \\
\hline & & & 2 & 10.63 & 0.64 & 1.6833 \\
\hline & & & 3 & 9.91 & 0.63 & 1.5857 \\
\hline & & & 4 & 9.63 & 0.62 & 1.5785 \\
\hline
\end{tabular}

strength $\left(\sigma_{\mathrm{c}}\right)$, the elastic modulus $(E)$, and the peak axial strain $\left(\varepsilon_{1 \max }\right)$ corresponding to the strain at peak stress. In accordance with the numerical results listed in Table 4, generally, the deformation and strength behaviors of specimens are found depending on the drilling arrangement.
3.3.2. Influences of Drilling Arrangements on the Strength and Deformation Parameters. Figure 6 shows the influence of the drilling diameter on the mechanical properties of specimens. From Figure 6, it can be seen that the elastic modulus remains stable with the increase of drilling diameter. The uniaxial 


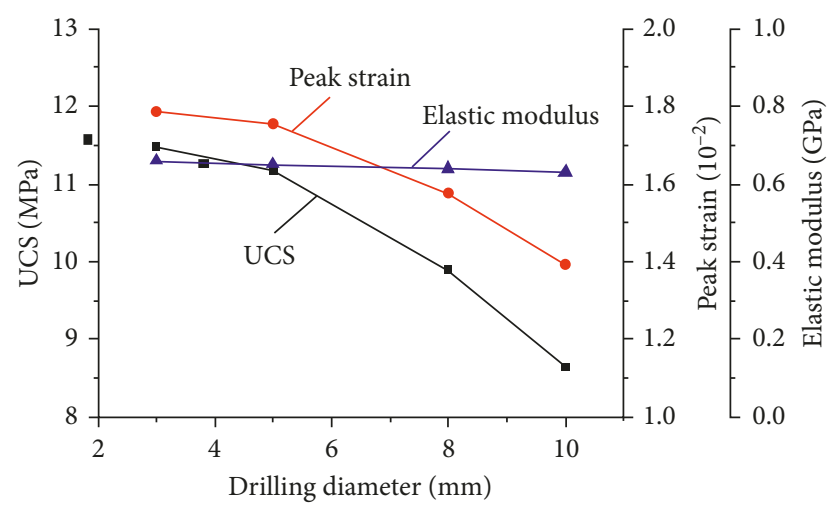

Figure 6: Influence of drilling diameter on the mechanical properties of specimens. UCS: uniaxial compressive strength.

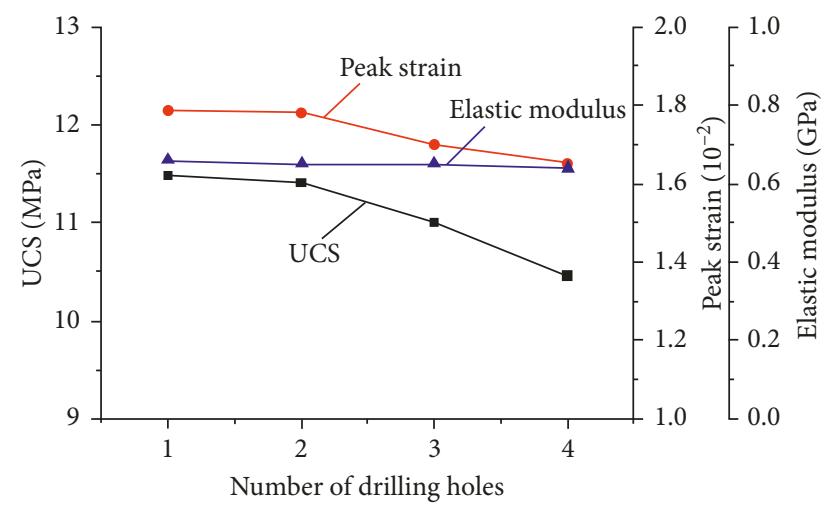

Figure 7: Influence of number of drilling holes in one row on the mechanical properties of specimens.

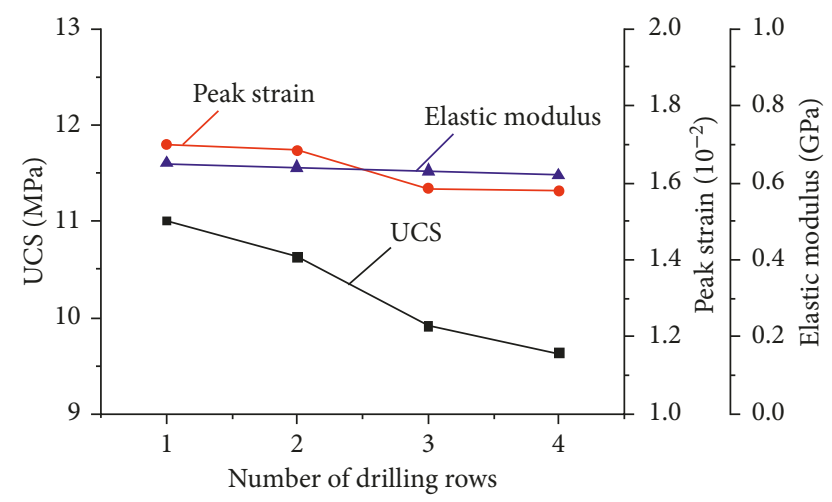

FIGURE 8: Influence of number of drilling rows on the mechanical properties of specimens.

compressive strength and peak strain, however, show a different trend. Both of the two parameters decrease gradually with the increase of drilling diameter. For example, when the drilling diameter increases from 3 to $10 \mathrm{~mm}$, the uniaxial compressive strength and peak strain vary from 11.48 to $8.64 \mathrm{MPa}$ and from 1.7863 to $1.3926 \times 10^{-2}$, respectively. In addition, the decreasing percentage of uniaxial compressive strength is $0.78-25.32 \%$ compared with the intact specimen.
Figure 7 shows the influence of number of drilling holes in one row on the mechanical properties of specimens. From Figure 7, it can be seen that the elastic modulus remains stable with the increase of number of drilling holes in one row, whose variation law is similar to the influence of drilling diameter. In contrast, the uniaxial compressive strength and peak strain remain steady first and then decrease gradually as increasing the number of drilling holes in one row. When the number of drilling holes increases from 1 to 2, the uniaxial compressive strength and peak strain vary from 11.48 to $11.41 \mathrm{MPa}$ and 1.7863 to $1.7804 \times 10^{-2}$, but when the number increases from 2 to 4 , these two parameters decrease from 11.41 to $10.46 \mathrm{MPa}$ and from 1.7804 to $1.6510 \times 10^{-2}$, respectively. Compared with the intact specimen, the decreasing percentage of uniaxial compressive strength is only $0.78-9.59 \%$, which is far lesser than the cause of increasing the drilling diameter.

Figure 8 shows the influence of number of drilling rows on the mechanical properties of specimens. From Figure 8, it can be seen that the deformation parameters, that is, the elastic modulus and peak strain, are not obviously influenced by the number of drilling rows. But, the uniaxial compressive strength decreases gradually with the increase of number of drilling rows. For example, as the number of drilling rows increases from 1 to 4 , the uniaxial compressive strength decreases from 11.01 to $9.63 \mathrm{MPa}$. Compared with the intact specimen, the decreasing percentage of the uniaxial compressive strength is only $4.84-16.77 \%$.

\subsubsection{Influences of Drilling Arrangements on Failure} Modes. Figure 9 gives the failure modes of specimens with various drilling arrangements. Figures 9(a) and 9(b) clearly show that the influence of drilling diameter or number of drilling holes in one row on the failure mode of specimens is not obvious. For specimens with different drilling diameters, shear failure accompanied with splitting failure is the main failure mode and the shear zone just propagates across the drilling hole, but for specimens with different numbers of drilling holes in one row, splitting failure accompanied with shear failure is the main failure mode. However, the number of drilling rows influences the failure mode of specimens greatly, as shown in Figure 9(c). When the number of drilling rows is 1 or 3 , splitting failure is the main failure mode, but when the number of drilling rows is 2 or 4 , shear failure is the main failure mode.

\section{Influences of Drilling Arrangements on the Energy Evolution}

4.1. Energy Parameters. Although scholars have proposed many indexes for evaluating the bursting liability of coal seam, there are little researches related to the bursting liability evaluation of destressed coal seam. Zhu et al. [16] put forward a new index, that is, dissipation energy index $\left(X_{\mathrm{E}}\right)$, to improve this issue. This index is used in this section to analyze the influences of drilling arrangements on the energy evolution of specimens before peak stress. $X_{\mathrm{E}}$ is the ratio of the released accumulative strain energy after destressing $(\Delta S)$ to the accumulated strain energy before destressing $\left(S_{1}\right)$, as shown in Figure $10(\mathrm{a}) . X_{\mathrm{E}}$ is calculated in the following equation: 

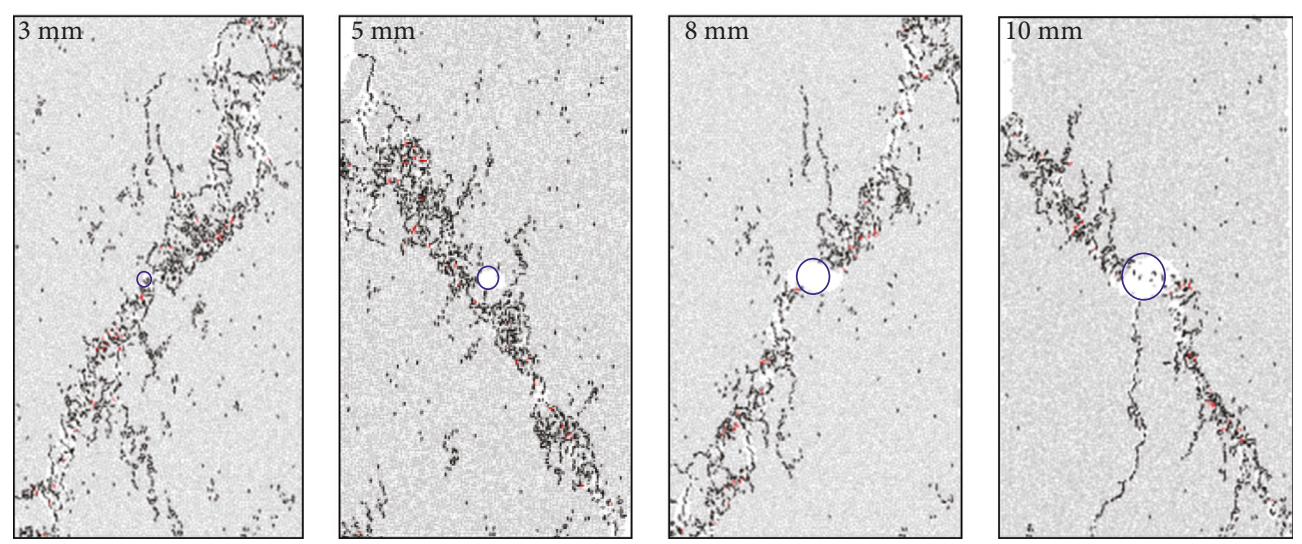

(a)
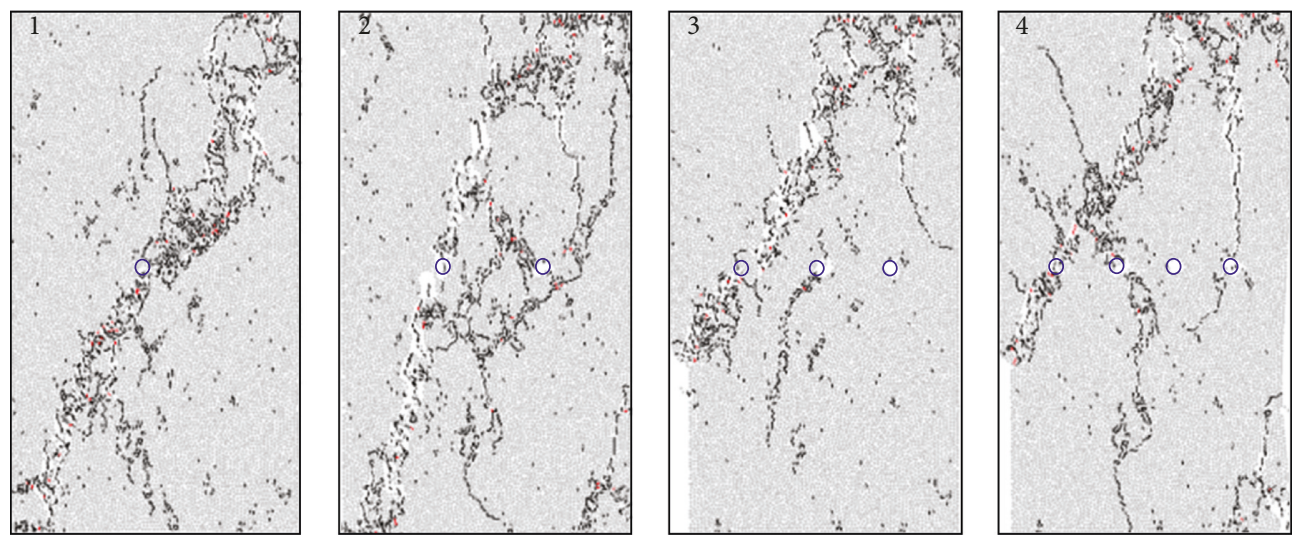

(b)
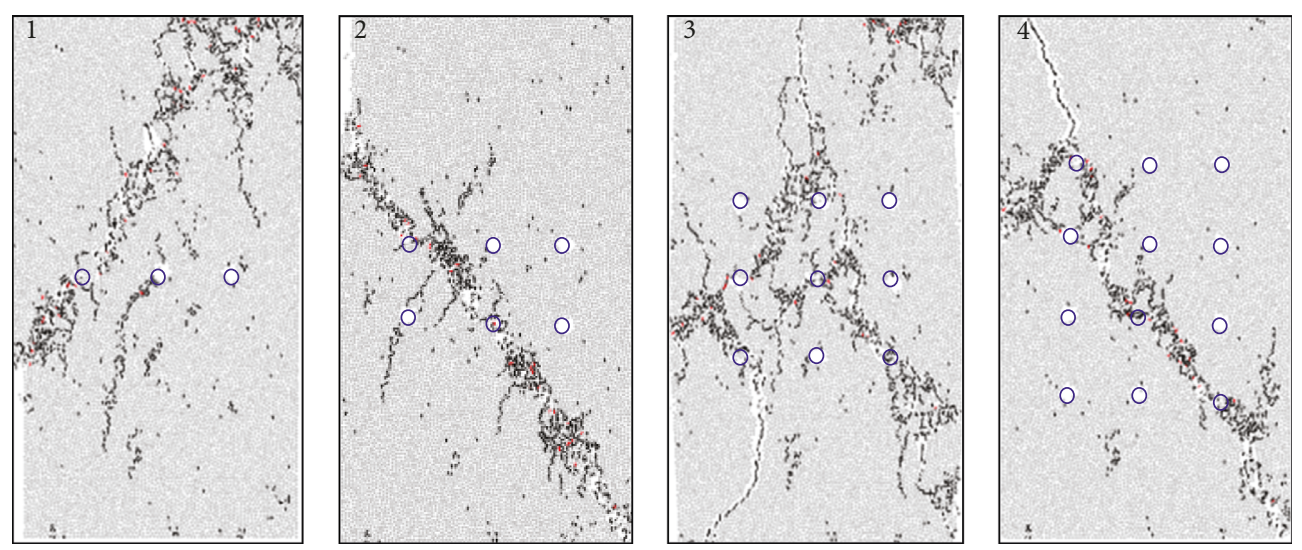

(c)

FIGURE 9: Failure modes of specimens with various drilling arrangements. (a) Different drilling diameters. (b) Different numbers of drilling holes in one row. (c) Different numbers of drilling rows.

$$
X_{\mathrm{E}}=\frac{\Delta S}{\left(\Delta S+S_{1}\right)} \times 100 \% .
$$

Besides using the above index, the bursting energy index $\left(K_{\mathrm{E}}\right)$ also is used to study the influences of drilling arrangements on the energy evolution. As shown in Figure 10(b), $K_{\mathrm{E}}$ refers to the ratio of the accumulative strain energy before peak stress $\left(F_{\mathrm{S}}\right)$ to the released energy after peak stress $\left(F_{\mathrm{X}}\right)$ under uniaxial compression condition [30, 31]. This index considers the energy transformation during the deformation and failure processes of rock or coal specimens. $K_{\mathrm{E}}$ is calculated in the following equation:

$$
K_{\mathrm{E}}=\frac{F_{\mathrm{S}}}{F_{\mathrm{X}}} .
$$

4.2. Influences of Drilling Arrangements. Employing (1) and (2), the dissipation energy and bursting energy indexes of specimens with different drilling arrangements are determined 


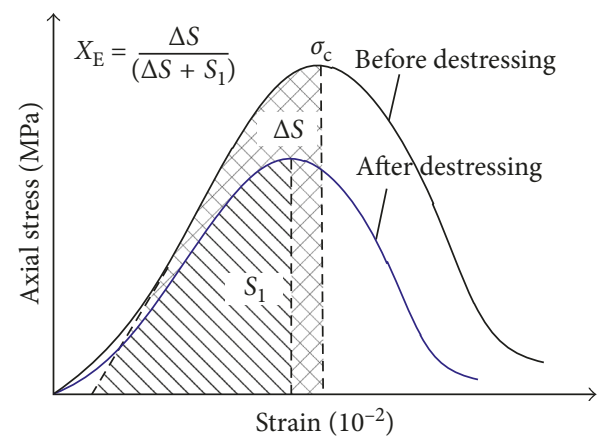

(a)

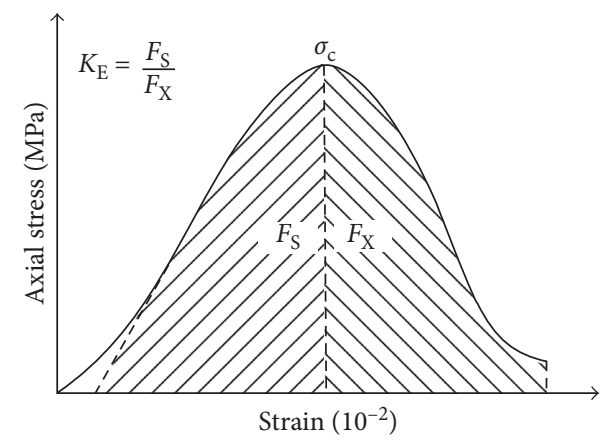

(b)

Figure 10: Sketch of the calculations of $X_{\mathrm{E}}$ and $K_{\mathrm{E}}$. (a) Calculation of $X_{\mathrm{E}}$. (b) Calculation of $K_{\mathrm{E}}$.

TABLE 5: Energy indexes of specimens with different drilling arrangements.

\begin{tabular}{|c|c|c|c|c|c|c|c|}
\hline Test scheme & $R_{\mathrm{D}}(\mathrm{mm})$ & $N_{\mathrm{H}}$ & $N_{\mathrm{R}}$ & $X_{\mathrm{E}}(\%)$ & $F_{\mathrm{S}}\left(\mathrm{MJ} / \mathrm{mm}^{3}\right)$ & $F_{\mathrm{X}}\left(\mathrm{MJ} / \mathrm{mm}^{3}\right)$ & $K_{\mathrm{E}}$ \\
\hline \multirow{4}{*}{ I } & 3 & \multirow{4}{*}{1} & \multirow{4}{*}{1} & 1.01 & 0.1023 & 0.0112 & 9.13 \\
\hline & 5 & & & 3.35 & 0.0953 & 0.0121 & 7.87 \\
\hline & 8 & & & 24.35 & 0.0787 & 0.0110 & 7.17 \\
\hline & 10 & & & 41.93 & 0.0600 & 0.0150 & 4.00 \\
\hline \multirow{4}{*}{ II } & \multirow{4}{*}{3} & 1 & \multirow{4}{*}{1} & 1.01 & 0.1023 & 0.0112 & 9.13 \\
\hline & & 2 & & 2.51 & 0.1008 & 0.0112 & 9.00 \\
\hline & & 3 & & 10.12 & 0.0929 & 0.0106 & 8.76 \\
\hline & & 4 & & 14.89 & 0.0890 & 0.0115 & 7.74 \\
\hline \multirow{4}{*}{ III } & \multirow{4}{*}{3} & \multirow{4}{*}{3} & 1 & 10.12 & 0.0929 & 0.0106 & 8.76 \\
\hline & & & 2 & 13.36 & 0.0895 & 0.0075 & 11.93 \\
\hline & & & 3 & 23.71 & 0.0788 & 0.0161 & 4.89 \\
\hline & & & 4 & 26.17 & 0.0763 & 0.0075 & 10.17 \\
\hline
\end{tabular}

and summarized in Table 5. Figure 11 depicts the energy evolution curves of these specimens with various drilling arrangements.

As shown in Figures 11(a) and 11(b), influences of drilling diameter or the number of drilling holes in one row on the energy evolution law are similar. As increasing the drilling diameter or number of drilling holes in one row, the energy dissipation index increases nonlinearly. When the drilling diameter and number of drilling holes increase from 3 to $5 \mathrm{~mm}$ and from 1 to 2 , respectively, their corresponding variations of energy dissipation index are only $1.01-3.35 \%$ and $1.01-2.51 \%$. But when the drilling diameter and number of drilling holes increase from 8 to $10 \mathrm{~mm}$ and from 3 to 4 , the corresponding variations reach about $24.35-41.93 \%$ and $10.12-14.89 \%$, respectively. However, the bursting energy index first decreases slowly and then rapidly as increasing the drilling diameter or number of drilling holes in one row, which shows an opposite trend compared with the energy dissipation index. For example, when the drilling diameter varies from 3 to $8 \mathrm{~mm}$, the bursting energy index decreases from 9.13 to 7.17 , but when the drilling diameter is $10 \mathrm{~mm}$, this index is only 4.00 ; when the number of drilling holes in one row increases from 1 to 4 , the bursting energy index varies from 9.13 to 7.74 . This phenomenon reveals that increasing the drilling diameter for the destress drilling method might be more effective than increasing the number of drilling holes in one row.

Although the energy dissipation index also increases as increasing the number of drilling rows, the variation law of bursting energy index is not obvious, as shown in Figure 11(c). When the number of drilling rows increases from 1 to 4 , the energy dissipation index varies from $10.12 \%$ to $26.17 \%$, but the bursting energy index first increases from 8.76 to 11.93 and decreases to 4.89 and then increases to 10.17 . This phenomenon is very interesting. Perhaps there are two reasons causing this result. First, as increasing the number of defects of specimens, its bearing capacity will be weakened, certainly causing the decrease of ability of strain energy accumulation. Second, the influence of the number of drilling rows on the failure modes is more serious than that of the drilling diameter or number of drilling holes in one row, but the energy consumed by the failure of specimens varies greatly depending on the failure modes. For example, when the number of drilling rows is 2 , the failure mode is shear failure and the bursting energy index is high. This result shows that choosing a proper drilling arrangement is essential for mitigating rock bursts; that is, if the drilling arrangement that leads to the energy consumed by the coal failure is small, rock bursts might occur.

\section{Discussions}

As introduced in Section 2, the prevention mechanism of destress drilling performed in coal seam is given in Figure 1. We can explain the influence of drilling arrangements on the prevention mechanism of the drilling method based on the above results. Overall, the strain accumulation ability of 


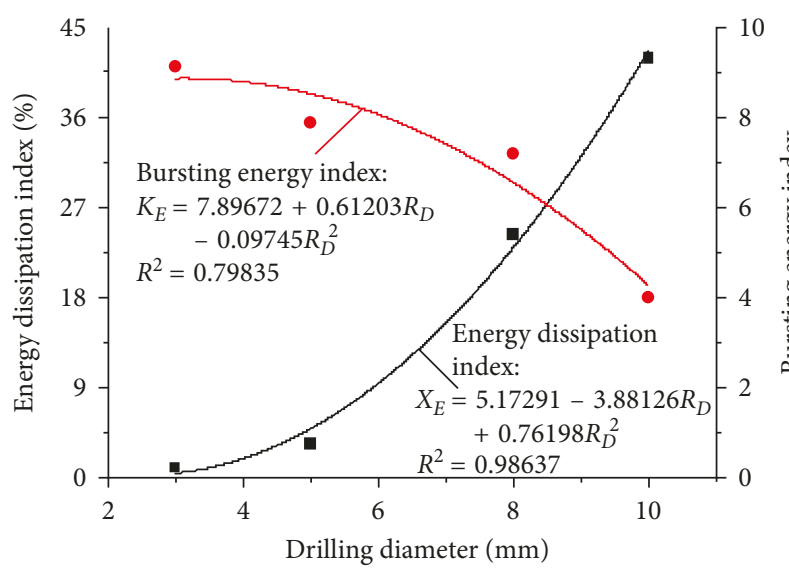

(a)

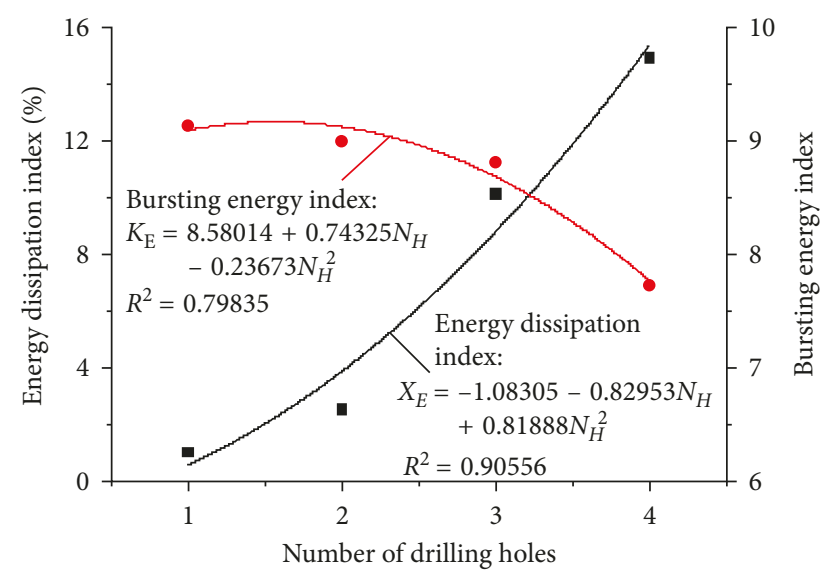

(b)

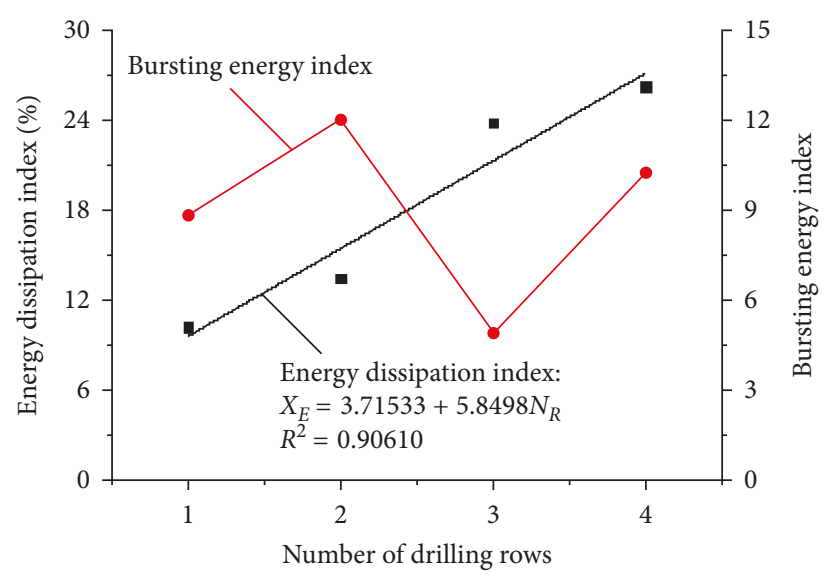

(c)

FIgURE 11: Energy evolution curves of specimens with various drilling arrangements. (a) Different drilling diameters. (b) Different numbers of drilling holes in one row. (c) Different numbers of drilling rows.

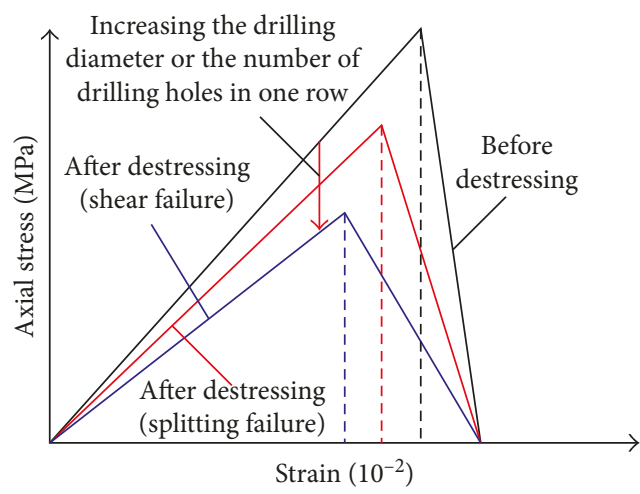

(a)

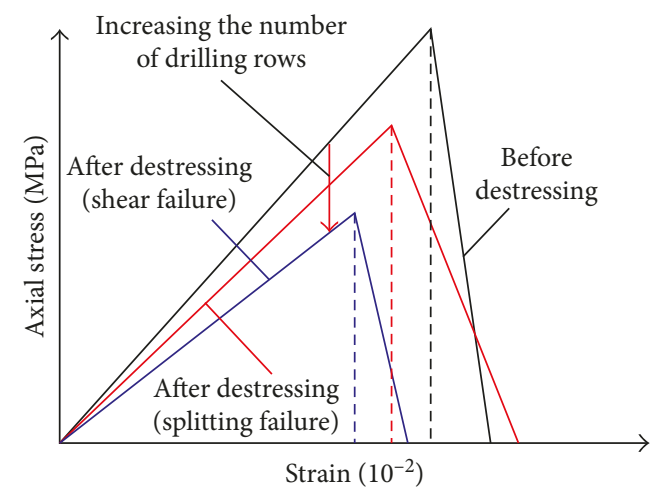

(b)

FIGURE 12: Sketch of the influencing mechanism of drilling arrangement on the prevention mechanism of destress drilling method. (a) Different drilling diameters and numbers of drilling holes in one row. (b) Different numbers of drilling rows.

coal seam decreases nonlinearly with the increase of the number or area of defects, but its decreasing degree varies greatly depending on the drilling arrangement. In addition, the drilling arrangement also influences the consumed energy of coal failure through affecting the failure mode, especially for the number of drilling rows.

In aspect of the influences of drilling diameter and number of drilling holes in one row, their influencing 
mechanisms are similar. Although the strain accumulation ability of coal decreases with the increase of drilling diameter or number of drilling holes in one row, the failure mode of coal almost remains stable. That means the variation of consumed energy of coal failure is small according to the least energy principle of dynamic failure of rock mass [32-34]. That is to say, the influencing mechanism of increasing the drilling diameter or number of drilling holes in one row mainly is to decrease the energy accumulation ability of coal without affecting the consumed energy of coal failure, as shown in Figure 12(a). Therefore, the bursting liability of coal seam can be weakened. However, the influencing mechanism of number of drilling rows shows a difference in the consumed energy of coal failure through affecting the failure mode. As increasing the number of drilling rows, if the coal failure consumes lesser energy than before, the bursting energy index may increase, and vice versa. This result is mainly influenced by the failure mode, as shown in Figure 12(b). So far, Figure 12 gives the influencing mechanism of drilling arrangement on the prevention mechanism of destress drilling method.

\section{Conclusions}

In this study, the rock burst mitigation mechanism of the destress drilling method performed in coal seam was first introduced. Then, a systematic numerical simulation by PFC2D was conducted to research the mechanical properties of coal models with various drilling arrangements under uniaxial compression tests. The following conclusions can be summarized:

(1) The drilling arrangement mainly influences the bearing capacity of coal models. The uniaxial compressive strength increases nonlinearly with the increase of the drilling diameter, number of drilling holes in one row, or number of drilling rows. Among the three factors, the influencing degree in order from strong to weak is the drilling diameter, number of drilling holes in one row, and number of drilling rows. Compared with intact specimens, their decreasing percentages of uniaxial compressive strength are $0.78-25.31 \%, 4.84-16.78 \%$, and $0.78-9.59 \%$, respectively. However, the elastic modulus remains stable as increasing the number of these defects. This phenomenon might be caused by that materials are homogeneous and defects could only decrease the structural bearing capacity in simulating process.

(2) For specimens with different drilling diameters, shear failure accompanied with splitting failure is the main failure mode, but for specimens with different numbers of drilling holes in one row, splitting failure accompanied with shear failure is the main failure mode. However, it might be splitting or shear failure for specimens with different numbers of drilling rows.

(3) The energy dissipation index increases nonlinearly with the increase of drilling diameter or number of drilling holes in one row, but the bursting energy index shows an opposite variation law, which decreases slowly and then rapidly. In addition, the energy dissipation index increases linearly as increasing the number of drilling rows, but the variation law of bursting energy index is not obvious due to the influence of different failure modes.

(4) The influencing mechanism of drilling diameter or number of drilling holes in one row on the prevention mechanism of the destress drilling method is to decrease the energy accumulation ability of coal without affecting the consumed energy of coal failure, as shown in Figure 12(a). However, the number of drilling rows influences not only the energy accumulation ability, but also the consumed energy of coal failure, as shown in Figure 12(b). As increasing the number of drilling rows, if the coal failure consumes lesser energy than before, the bursting energy index might increase, and vice versa.

Although the analysis results above all were obtained by numerical simulation, it still reveals some variation laws about the influences of various drilling arrangements on the mechanical properties and failure mechanisms of specimens. We all know that the homogeneity of rock or rock-like materials is often hard to be controlled, but in the PFC2D numerical simulation process, the material is homogeneous. Thus, we can study the influences of drilling arrangements without influences of other factors, especially material differences. Therefore, the results obtained in this paper can also provide a reference for understanding the influencing mechanism of drilling arrangement on the rock burst mitigation mechanism of the destress drilling method. Of course, we will continue to do laboratory tests in the future to enrich the research and prove the viewpoint in this paper.

\section{Disclosure}

Tong-bin Zhao and Wei-yao Guo are co-first authors.

\section{Conflicts of Interest}

The authors declare no conflicts of interest.

\section{Acknowledgments}

The research described in this paper was financially supported by State Key Research Development Program of China (no. 2016YFC0801401), National Natural Science Foundation of China (nos. 51674160, 51474137, and 51704181), Shandong Province Natural Science Foundation (no. ZR2017BEE013), Tai'shan Scholar Engineering Construction Fund of Shandong Province of China (no. ts201511026), Scientific Research Foundation of Shandong University of Science and Technology for Recruited Talents (2017RCJJ014), Open Fund Research Project of State Key Laboratory Breeding Base for Mining Disaster Prevention and Control (MDPC201711) and Taishan Scholar Talent Team Support Plan for Advantaged \& Unique Discipline Areas. 


\section{References}

[1] W. P. Huang, Q. Yuan, Y. L. Tan et al., “An innovative support technology employing a concrete-filled steel tubular structure for a 1000-m-deep roadway in a high in situ stress field," Tunnelling and Underground Space Technology, vol. 73, pp. 26-36, 2018.

[2] C. P. Lu, G. J. Liu, Y. Liu, N. Zhang, J. H. Xue, and L. Zhang, "Microseismic multi-parameter characteristics of rockburst hazard induced by hard roof fall and high stress concentration," International Journal of Rock Mechanics and Mining Sciences, vol. 76, pp. 18-32, 2015.

[3] Y. L. Tan, F. H. Yu, J. G. Ning, and T. B. Zhao, "Design and construction of entry retaining wall along a gob side under hard roof stratum," International Journal of Rock Mechanics and Mining Sciences, vol. 77, pp. 115-121, 2015.

[4] T. B. Zhao, W. Y. Guo, Y. L. Tan, Z. Zhang, and K. K. Cheng, "Research on the mechanics mechanism of rock burst for mining in the variable region of coal thickness," Journal of China Coal Society, vol. 41, no. 7, pp. 1659-1666, 2016.

[5] T. B. Zhao, W. Y. Guo, Y. L. Tan, Y. C. Yin, L. S. Cai, and J. F. Pan, "Case studies of rock bursts under complicated geological conditions during multi-seam mining at a depth of 800 m," Rock Mechanics and Rock Engineering, pp. 1-26, 2018.

[6] F. Z. Meng, H. Zhou, Z. Q. Wang et al., "Experimental study on the prediction of rockburst hazards induced by dynamic structural plane shearing in deeply buried hard rock tunnels," International Journal of Rock Mechanics and Mining Sciences, vol. 86, pp. 210-223, 2016.

[7] Y. L. Tan, X. S. Liu, J. G. Ning, and Y. W. Lu, "In situ investigations on failure development of overlying strata induced by mining multiple coalseams," Geotechnical Testing Journal, vol. 40, no. 2, pp. 244-257, 2017.

[8] J. G. Ning, J. Wang, J. Q. Jiang, S. C. Hu, L. S. Jiang, and X. S. Liu, "Estimation of crack initiation and propagation thresholds of confined brittle coal specimens based on energy dissipation theory," Rock Mechanics and Rock Engineering, vol. 51, no. 1, pp. 119-134, 2018.

[9] G. L. Feng, X. T. Feng, B. R. Chen, and Y. X. Xiao, "Microseismic sequences associated with rockbursts in the tunnels of the Jinping II hydropower station," International Journal of Rock Mechanics and Mining Sciences, vol. 80, pp. 89-100, 2015.

[10] G. L. Feng, X. T. Feng, B. R. Chen, Y. X. Xiao, and Y. Yu, "A microseismic method for dynamic warning of rockburst development processes in tunnels," Rock Mechanics and Rock Engineering, vol. 48, no. 5, pp. 2061-2076, 2015.

[11] J. H. Liu, F. X. Jiang, G. J. Sun, Z. G. Zhang, and W. F. Tan, "Mechanism of intensive venting pulverized coal to prevent coal burst and its application," Chinese Journal of Rock Mechanics and Engineering, vol. 33, no. 4, pp. 747-754, 2014.

[12] T. B. Zhao, W. Y. Guo, Y. L. Tan, C. P. Lu, and C. W. Wang, "Case histories of rock bursts under complicated geological conditions," Bulletin of Engineering Geology and the Environment, pp. 1-17, 2017.

[13] W. Y. Guo, T. B. Zhao, Y. L. Tan, F. H. Yu, S. C. Hu, and F. Q. Yang, "Progressive mitigation method of rock bursts under complicated geological conditions," International Journal of Rock Mechanics and Mining Sciences, vol. 96, pp. 11-22, 2017.

[14] Z. G. Liu, A. Y. Cao, G. A. Zhu, and C. B. Wang, "Numerical simulation and engineering practice for optimal parameters of deep-hole blasting in sidewalls of roadway," Arabian Journal for Science and Engineering, vol. 42, no. 9, pp. 3809-3818, 2017.
[15] P. Konicek, K. Soucek, L. Stas, and R. Singh, "Long-hole destress blasting for rockburst control during deep underground coal mining," International Journal of Rock Mechanics and Mining Sciences, vol. 61, pp. 141-153, 2013.

[16] S. T. Zhu, F. X. Jiang, X. F. Shi et al., "Energy dissipation index method for determining rockburst prevention drilling parameters," Rock and Soil Mechanics, vol. 36, no. 8, pp. 2270-2276, 2015.

[17] C. Y. Jia, Y. J. Jiang, X. P. Zhang, D. Wang, H. J. Luan, and C. S. Wang, "Laboratory and numerical study on pressure relief mechanism of large-hole diameter drill hole," Chinese Journal of Geotechnical Engineering, vol. 39, no. 6, pp. 1115-1122, 2017, http://www.cnki.net/kcms/detail/32.1124.TU.20160917.1119. 002.html.

[18] H. G. Liu, Y. N. He, J. H. Xu, and L. J. Han, "Numerical simulation and industrial test of boreholes destressing technology in deep coal tunnel," Journal of China Coal Society, vol. 32, no. 1, pp. 33-37, 2007.

[19] J. K. Li, Z. H. Xiong, D. S. Liu, and X. B. Li, "Numeric simulation of borehole pressure relief preventing roadway rockburst of a mine," Journal of Xi'an University of Science and Technology, vol. 29, no. 4, pp. 424-426, 2009.

[20] E. B. Yi, Z. L. Mu, L. M. Dou, J. G. Ju, L. Xie, and D. L. Xu, "Study on comparison and analysis on pressure releasing effect of boreholes in soft and hard seam," Coal Science and Technology, vol. 39, no. 6, pp. 1-5, 2011.

[21] X. X. Song, Y. J. Zuo, and X. Wang, "Numerical simulation of pressure-released hole combined support with rockbolt in deep roadway with dynamic disturbance," Journal of Central South University of Technology, vol. 45, no. 9, pp. 3158-3165, 2014.

[22] Q. Z. Ma, Y. D. Jiang, Y. W. Li, and Y. M. Yang, "Collaborative control of pressure-released boreholes with u-steel of roadways in ultra-soft coal seam," Journal of China Coal Society, vol. 40, no. 10, pp. 2279-2286, 2015.

[23] Q. H. Zhu, W. B. Lu, J. S. Sun, Y. Luo, and M. Chen, "Prevention of rockburst by guide holes based on numerical simulations," International Journal of Mining Science and Technology, vol. 19, no. 3, pp. 346-351, 2009.

[24] T. B. Zhao, W. Y. Guo, Y. C. Yin, and Y. L. Tan, "Bolt pull-out tests of anchorage body under different loading rates," Shock and Vibration, vol. 2015, Article ID 121673, 8 pages, 2015.

[25] S. C. Hu, Y. L. Tan, H. Zhou et al., "Impact of bedding planes on mechanical properties of sandstone," Rock Mechanics and Rock Engineering, vol. 50, no. 8, pp. 2243-2251, 2017.

[26] X. P. Zhang and L. N. Y. Wong, "Loading rate effects on cracking behavior of flaw-contained specimens under uniaxial compression," International Journal of Fracture, vol. 180, pp. 93-110, 2013.

[27] T. B. Zhao, Y. C. Yin, Y. L. Tan, and Y. M. Song, "Deformation tests and failure process analysis of an anchorage structure," International Journal of Mining Science and Technology, vol. 25, no. 2, pp. 237-242, 2015.

[28] T. B. Zhao, W. Y. Guo, Y. L. Tan, F. H. Yu, B. Huang, and L. S. Zhang, "Failure mechanism of layer-crack rock models with different vertical fissure geometric configurations under uniaxial compression," Advances in Mechanical Engineering, vol. 9, no. 11, pp. 1-15, 2017.

[29] R. H. Cao and H. Lin, "Experimental and numerical study of failure behavior and energy mechanics of rock-like materials containing multiple joints," Advances in Materials Science and Engineering, vol. 2017, Article ID 6460150, 17 pages, 2017.

[30] Y. L. Tan, W. Y. Guo, Q. H. Gu et al., "Research on the rockburst tendency and $\mathrm{AE}$ characteristics of inhomogeneous 
coal-rock combination bodies," Shock and Vibration, vol. 2016, Article ID 9271434, 11 pages, 2016.

[31] W. Y. Guo, Y. L. Tan, Z. L. Yang, T. B. Zhao, and S. C. Hu, "Effect of saturation time on the bursting liability indexes of coal and its application for rock burst mitigation," Geotechnical and Geological Engineering, vol. 36, no. 1, pp. 589597, 2017.

[32] Y. S. Zhao, Z. C. Feng, and Z. J. Wan, "Least energy principle of dynamical failure of rock mass," Chinese Journal of Rock Mechanics and Engineering, vol. 22, no. 11, pp. 1781-1783, 2003.

[33] G. C. Zhang, S. J. Liang, Y. L. Tan, and F. X. Xie, "Numerical modeling for longwall pillar design: a case study from a typical longwall panel in China," Journal of Geophysics and Engineering, vol. 15, no. 1, pp. 125-134, 2018.

[34] H. Lin, W. Xiong, and Q. X. Yan, "Modified formula for the tensile strength as obtained by the flattened Brazilian disc test," Rock Mechanics and Rock Engineering, vol. 49, no. 4, pp. 1579-1586, 2016. 


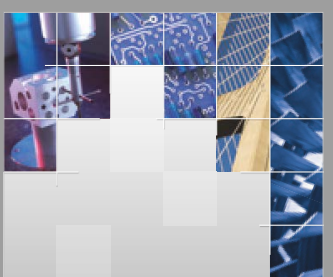

\section{Enfincering}
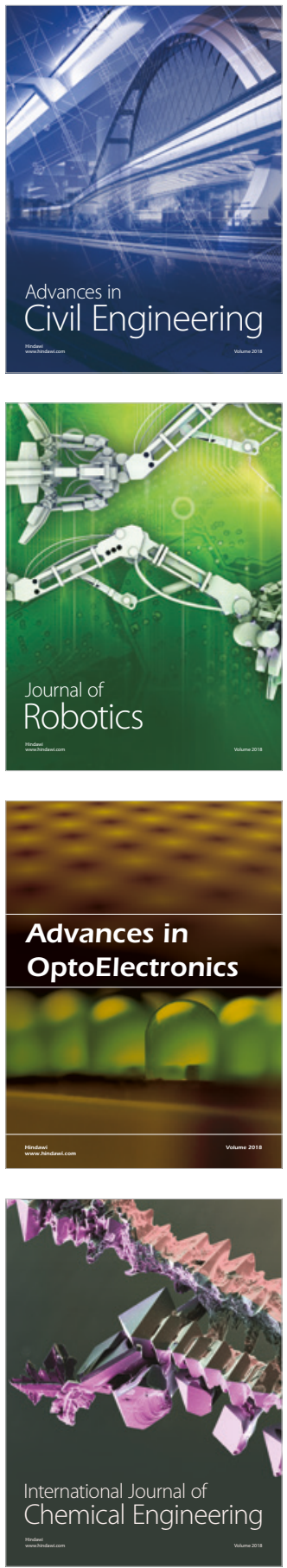

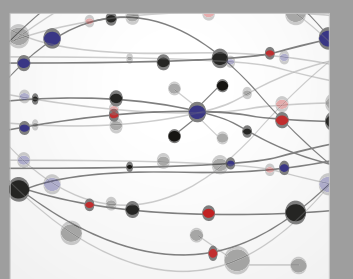

\section{Rotating \\ Machinery}

The Scientific World Journal

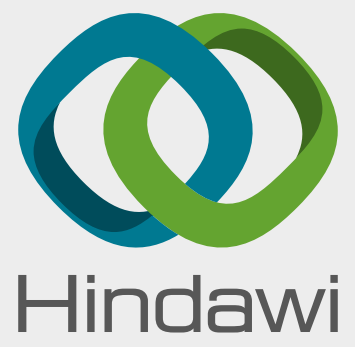

Submit your manuscripts at

www.hindawi.com
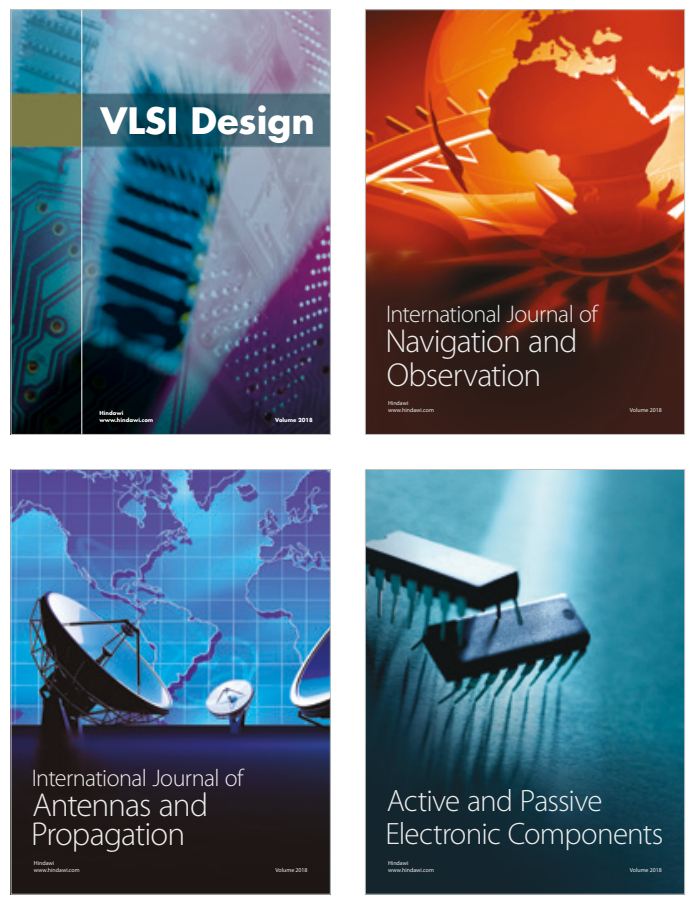
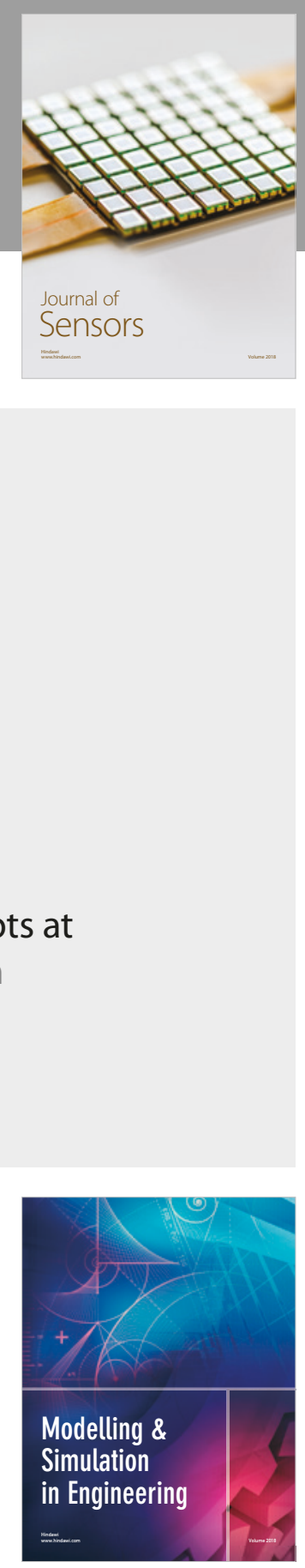

\section{Advances \\ Multimedia}
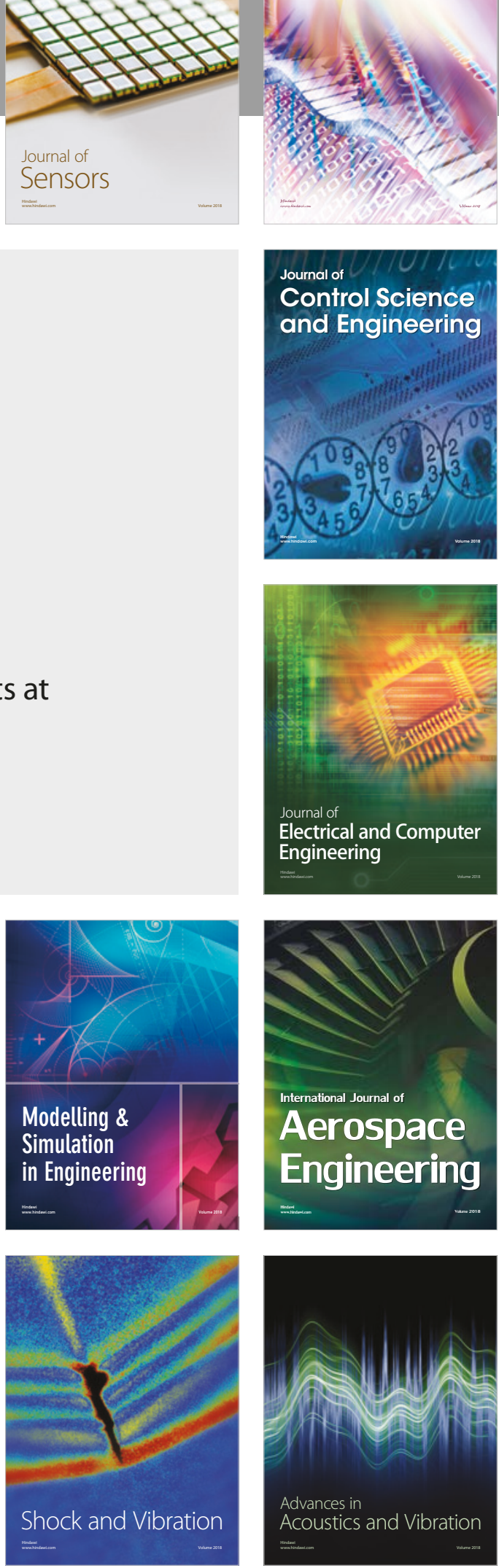